\title{
Local rates of ice-sheet thickness change in Greenland
}

\author{
Gordon. S. HAMILTON, ${ }^{*}$ IAN. M. WHILLANS ${ }^{\dagger}$ \\ Byrd Polar Research Center and Department of Geological Sciences, The Ohio State University, 1090 Carmack Road, \\ Columbus, OH 43210-1002, U.S.A. \\ E-mail: gordon.hamilton@maine.edu
}

\begin{abstract}
The rate of ice-sheet thickness change is calculated for 10 sites in Greenland by comparing measured values of ice vertical velocity and snow-accumulation rate. Vertical velocities are derived from repeat surveys of markers using precision global positioning system techniques, and accumulation rates are determined from stratigraphic analysis of firn cores. The results apply to time-scales covered by the firn-core records, which in most cases are a few decades. A spectrum of thickness-change rates is obtained, ranging from substantial thinning to slow thickening. The sites where ice-sheet thinning is indicated are located near the ice-sheet margin or in outlet glacier catchments. Interior and high-elevation sites are predominantly in balance or thickening slowly. Uncertainties in the rates of thickness change are dominated by errors in the determination of accumulation rates. The results of this work are broadly comparable with regional estimates of mass balance obtained from the analysis of catchment input vs discharge.
\end{abstract}

\section{INTRODUGTION}

Modern polar ice sheets play an important role in modulating global sea level. The Greenland ice sheet, for example, if completely melted would raise sea level by about $7.5 \mathrm{~m}$. Current estimates suggest that this ice sheet as a whole is very close to steady state (Thomas and others, 2000), although there is substantial spatial variability in the response of different regions of the ice sheet. Thus there is great interest in improving the understanding of current ice-sheet behavior.

The mass balance, or rate of thickening or thinning $(\mathrm{d} H / \mathrm{d} t)$, of an ice sheet is determined by the difference between input by snow accumulation and output by ice flow. Both quantities need to be measured with very good precision in order to calculate mass balance with small uncertainty. Until recently, these measurements were technically and logistically difficult to make.

The advent of precision global positioning system (GPS) surveying has overcome many of the technical and logistic issues relating to measurement of ice flow. A comprehensive study of basin-scale mass balance was conducted for the entire Greenland ice sheet by Thomas and others (2000), in which catchment fluxes calculated using GPS-derived horizontal velocities were compared with up-glacier accumulation rates. Hamilton and others (1998) and Hamilton and Whillans (2000) describe a technique, used in this paper, for calculating local rates of ice-sheet thickness change using precise GPS measurements of vertical velocity. Both tech-

* Present address: Institute for Quaternary and Climate Studies, University of Maine, 303 Bryand Global Sciences Center, Orono, ME 04469, U.S.A.

$\dagger$ Deceased. niques offer the ability to make quick, reliable and precise measurements of ice flow and therefore reduce the logistics burden of field-based mass-balance programs.

Ice-sheet mass balance is also being investigated by remote sensing, using satellite and airborne altimetry (Davis and others, 1998; Wingham and others, 1998; Zwally and others, 1998; Krabill and others, 2000). Altimetry involves repeat measurements of ice-sheet surface elevations over a period of time, typically $5-15$ years, which results in a history of elevation changes. The goal is to link elevation changes to changes in ice thickness, but, in order to do this, the results need careful interpretation to account for secular variations in snowfall and firn compaction (Arthern and Wingham, 1998; McConnell and others, 2000) and the short time-scale of observation. However, those methods have great promise for estimating short-time-scale thickness changes and mass balance.

A coordinated program, the Program for Arctic Regional Climate Assessment (PARCA; Thomas and others, 2001b) involves satellite, airborne and ground-based approaches to study the mass balance of the Greenland ice sheet. The present work is a component of the ground-based program. This paper updates earlier results for six sites in Greenland described in Hamilton and Whillans (2000), and reports results from a further four sites.

\section{METHODS}

An ice sheet in steady state retains a constant shape over time, whereby the downward motion of ice is balanced by an equal amount of snow accumulation at the surface. In this paper, rates of ice-sheet-thickness change at 10 sites in Greenland (Fig. 1) are calculated using field measurements of the vertical component of ice velocity and long-term snow-accumulation rates derived from ice-core stratigraphy. The methodology is described in detail by Hamilton and Whillans (2000). 


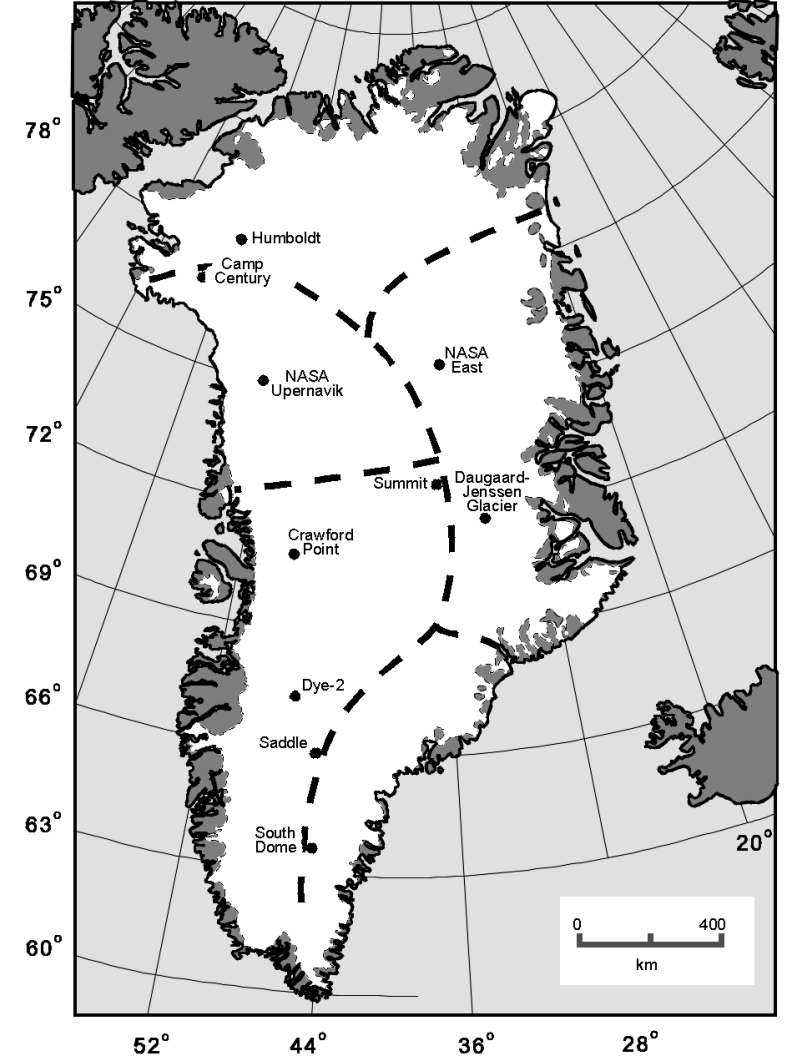

Fig. 1. Map showing the location of marker sites in Greenland. Dashed lines represent major drainage divides.

The vertical velocity of ice, $z$, is obtained from repeat GPS surveys of markers embedded 5-20 m deep in firn. Dualfrequency GPS data of 12 hours duration or longer are postprocessed using high-quality satellite orbit and clock parameters to provide precise point positions (Zumberge and others, 1997) of the markers. Surveys are conducted 1 year or more apart, yielding repeat positions from which marker motions (horizontal and vertical) are computed.

The vertical motions obtained from GPS surveys include the contributions of firn compaction beneath the markers and flow of the markers along slope. Both contributions must be removed to obtain the residual vertical velocity of ice (Hamilton and Whillans, 2000). The adjustment for compaction of firn beneath the markers is based on the principles of Sorge's law (Paterson, 1994), which predicts that at a given place and depth, density remains constant with time, assuming there is no change in accumulation rate or temperature. Using Sorge's law, the downward motion of a near-surface layer is equal to the long-term average accumulation rate, $b$, expressed as a mass per unit area, divided by the firn density, $\rho$, at that layer depth. Densities at marker depths are obtained from measurements of firn-core sample dimensions and mass. Depth-density profiles are smoothed using a Gaussian filter to remove small-scale fluctuations (Hamilton and Whillans, 2000), producing long-term average estimates of density with depth. Hamilton and Whillans (2000) test the applicability of Sorge's law to Greenland data and conclude that it is a reasonable approximation.

The component of vertical velocity due to along-slope flow is taken into account using the product of horizontal velocity, $u$, and surface slope, $\alpha$. Horizontal velocity is obtained from repeat GPS surveys of markers. Surface slope is obtained several ways. At Summit, slope is taken from a topographic map in Hodge and others (1990). For the marker sites at
Camp Century, NASA/Upernavik, Crawford Point and Dye-2, surface slopes are derived from airborne laser profiling (e.g. Krabill and others, 1995). In most cases, the flightlines are horizontally offset from the marker sites by a few hundred meters. The best estimate of slope is taken to be the nearest value (Hamilton and Whillans, 2000). For the remaining sites, surface slopes are obtained from optical leveling surveys. The slope component in the direction of ice flow is used. Slopes are averaged over distances equal to the horizontal displacements between surveys, except for cases where horizontal velocity is very slow. In these situations, slopes are averaged over $100 \mathrm{~m}$ to reduce the effects of small-scale surface roughness. Once these two adjustments for firn compaction and along-slope flow are made, the residual quantity is the vertical velocity of ice.

Snow-accumulation rates are derived from stratigraphic analyses of firn and ice cores and measurements of core density (Bales and others, 2001a). The vertical component of ice velocity is steady over long time-scales, so long-term values of accumulation rate are required. Snow-accumulation records of several centuries' duration are preferred, but these are difficult to obtain and are not available for all sites. In most instances, records spanning a few decades are used. Accumulation-rate records only a few years in length, such as those derived from pole burial rates or shallow snow pits, are unreliable because of secular variability (Van der Veen and Bolzan, 1999; Mosley-Thompson and others, 2001) and are not used here.

The lengths of the accumulation-rate records, which in most cases are a few decades, govern the time-scales of relevance for the calculated rates of thickness change. For a few sites, longer accumulation-rate records are available. The record at Summit spans several millennia (Meese and others, 1994), and records spanning a few centuries are available for Humboldt ( $\sim 850$ years), Camp Century ( 250 years) and NASA/U ( $\sim 350$ years) (Bales and others, 2001b).

\section{RESULTS}

Field measurements were made at 10 sites on the Greenland ice sheet (Fig. 1). The results are presented in Table 1. Some of the present results update previously reported values, taking into account revised accumulation-rate estimates and uncertainties. In particular, Hamilton and Whillans (2000) relied on assumed uncertainties in accumulation rates that are smaller than recently published values.

Calculated rates of ice-sheet thickness change range from substantial thinning to steady state to slow thickening. Sites relatively close to the ice-sheet periphery, or located in or close to the catchment basins of large outlet glaciers, generally show net thinning over the last few decades. This category includes Camp Century, Crawford Point and Daugaard-Jensen Gletscher (Table 1). Steady-state conditions and net thickening are calculated for sites located in the ice-sheet interior and at higher elevations. Summit, NASA/Upernavik and Humboldt (Fig. 1) all appear to be close to steady state. The fastest rates of ice-sheet thickening are calculated for sites in southern Greenland, such as South Dome, Saddle and Dye-2 (Fig. 1). Viewed together, the results from these 10 sites demonstrate a significant spatial variability of ice-sheet mass balance in Greenland.

Each calculated value of $\mathrm{d} H / \mathrm{d} t$ has an associated uncertainty (Table 1) derived from the combined uncertainties in 
Table 1. Data used to calculate rates of ice-sheet thickness change for one marker at each of ten sites in Greenland, using the equation $\mathrm{d} H / \mathrm{d} t=b / \rho+z+u \alpha$

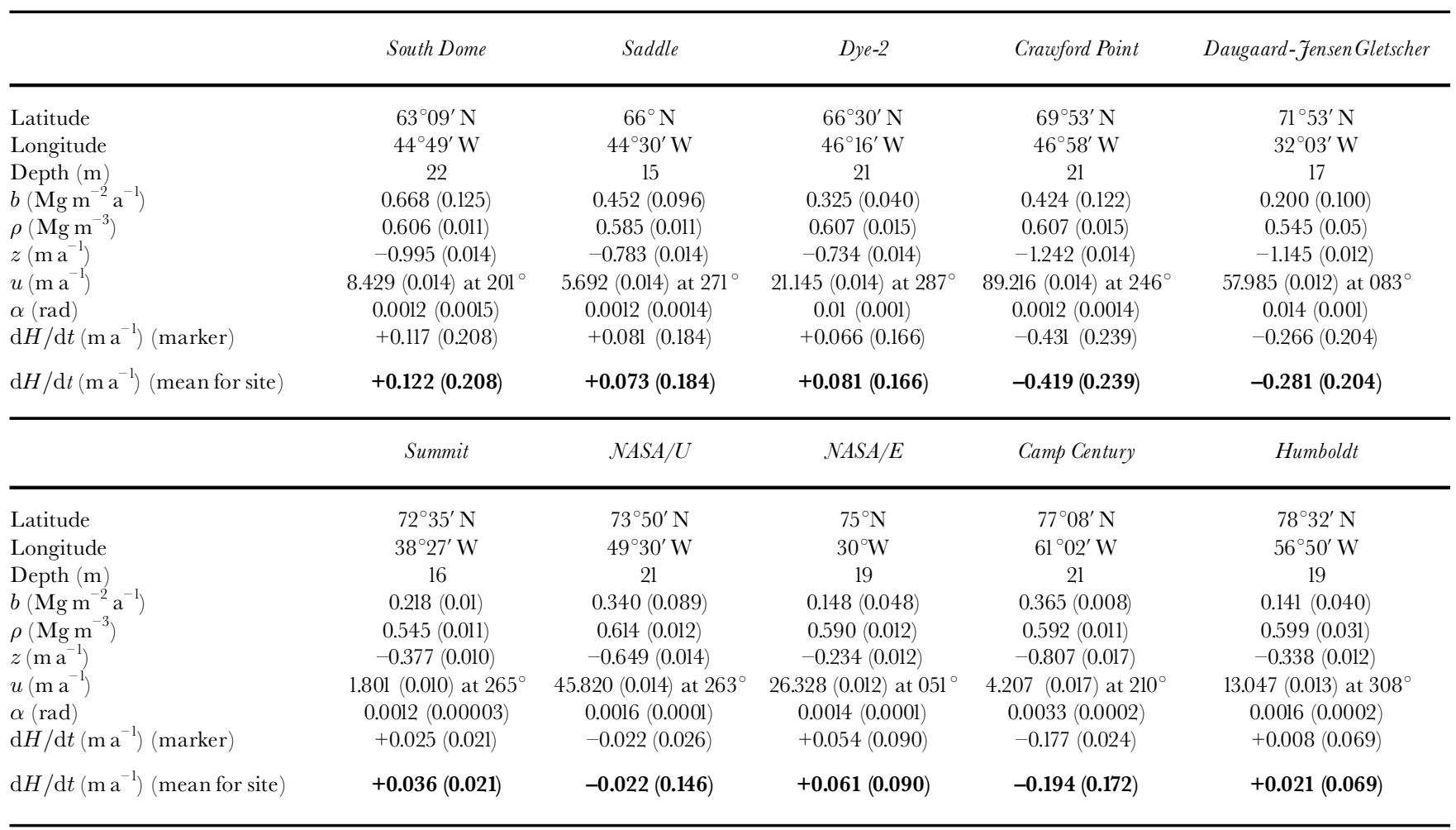

Notes: The mean rates of thickness change for all markers at a site are shown in bold along the bottom. $1 \sigma$ uncertainties are in parentheses.

GPS positioning (for horizontal and vertical velocities), firn density, accumulation rate and surface slope (Hamilton and Whillans, 2000). The error budget at most sites is dominated by uncertainties in the determination of accumulation rate. Bales and others (2001a) report that point estimates of accumulation rate have an uncertainty of about $24 \%$ for sites above $1800 \mathrm{~m}$ elevation. The level of uncertainty decreases for regions where accumulation rate is well constrained by multiple nearby cores. There are various causes for the relatively large errors in accumulation estimates, including core loss during drilling, misidentification of annual layers, and problems modeling depth-density profiles due to the presence of melt layers (Bales and others, 2001a). The uncertainty estimates used in the present calculations are probably maximum values. In principle, some of the uncertainty can be reduced by careful recovery of additional cores in the future.

Uncertainties in other measurements are less important, in most cases. GPS positioning of markers is a reliable technique that produces uncertainties of about $0.012 \mathrm{~m} \mathrm{a}^{-1}$ in the horizontal and vertical components of velocity. Errors in firn density are dominated by uncertainties in the measurement of core diameter, which, in the absence of reported values, are assumed to be $0.001 \mathrm{~m}$ (Hamilton and Whillans, 2000). The adjustment for vertical motion due to along-slope flow is usually made with confidence because horizontal velocity and surface slope have small uncertainties. However, in cases where the horizontal motion is relatively fast ( $\sim 30 \mathrm{~m} \mathrm{a}^{-1}$ or more), propagation of errors can lead to large uncertainties in this adjustment.

The minimum total uncertainty in $\mathrm{d} H / \mathrm{d} t$ is about $0.02 \mathrm{~m} \mathrm{a}^{-1}$, as calculated for Summit. This site is in a very slow-moving part of the ice sheet where measurements of each quantity have small errors. The largest uncertainties (about $0.21 \mathrm{~m} \mathrm{a}^{-1}$ ) are associated with rates of thickness change calculated at Crawford Point and Daugaard-Jensen Gletscher. Both of these sites are relatively fast-flowing, so the adjustments for along-slope flow propagate large uncertainties. At Daugaard-Jensen Gletscher an additional source of uncertainty is the lack of a direct measurement of accumulation rate. Pending the analysis of a core collected at this site, the present calculation uses an inferred accumulation rate derived from a contoured map of snow accumulation developed by Bales and others (2001b).

\section{GOMPARISON WITH OTHER RESULTS}

The present results refer to locally specific rates of ice-sheet thickness change over the last few decades and, in some cases, the last few centuries. Other techniques for determining ice-sheet mass balance yield results that apply to larger spatial scales or shorter time intervals.

Three other PARCA groups, each using different techniques, have prepared estimates of the mass balance of the Greenland ice sheet. Thomas and others (2000) employ the traditional input-output technique of comparing integrated catchment accumulation, based on interpolation of widely scattered firn-core measurements, with horizontal discharge based on GPS measurements of velocity. Their results provide average conditions over very large areas (30 $000 \mathrm{~km}^{2}$ or larger). Krabill and others (2000) conducted repeat airborne laser altimetry to derive estimates of surface elevation change for 5 year intervals in the 1990s. Technical capabilities of the laser ranging device and on-board aircraft navigation and positioning systems were sufficient to obtain locally specific rates of surface elevation change with good precision. Repeat radar altimetry from satellites was used by Davis and others (1998) and Zwally and others 
Table 2. Comparison between local estimates of mass balance (present study) and corresponding regional estimates (Thomas and others, 2000). 1б uncertainties are in parentheses

\begin{tabular}{lccc} 
Local site name & $\begin{array}{c}\text { Regional catchment size } \\
\mathrm{km}^{2}\end{array}$ & $\begin{array}{c}\text { Local } \mathrm{d} H / \mathrm{d} t \\
\mathrm{~m} \mathrm{a}^{-1}\end{array}$ & $\begin{array}{c}\text { Regional } \mathrm{d} H / \mathrm{d} t \\
\mathrm{~m} \mathrm{a}^{-1}\end{array}$ \\
\hline Saddle & 118917 & $+0.073(0.184)$ & $+0.066(0.027)$ \\
Dye-2 & 118917 & $+0.081(0.166)$ & $+0.066(0.027)$ \\
Crawford Point & 116401 & $-0.419(0.239)$ & $-0.062(0.027)$ \\
NASA/U & 67387 & $-0.022(0.146)$ & $+0.016(0.028)$ \\
Daugaard-Jensen Gl. & 83680 & $-0.281(0.204)$ & $+0.033(0.041)$ \\
NASA/E & 117372 & $+0.061(0.090)$ & $+0.021(0.006)$ \\
Camp Century & 131774 & $-0.194(0.172)$ & $-0.064(0.017)$ \\
Humboldt & 84463 & $+0.021(0.069)$ & $-0.002(0.013)$ \\
& & &
\end{tabular}

(1998) to infer surface elevation changes over a $\sim 10$ year interval from the late 1970s to 1988. Spatial averaging was necessary to reduce uncertainties in satellite ephemeres and errors associated with radar ranging over surface slopes that increase with distance from the ice-sheet interior. The resulting rates of elevation change refer to regions as large as $2500 \mathrm{~km}^{2}$. It is clear that the spatial and temporal scales relevant for each result complicate a comparison between the various techniques.

The results described by Thomas and others (2000) refer to the same time-scales as the present results; both techniques use common accumulation-rate data (Bales and others, 2001b). Qualitatively, there is good agreement between results from the two techniques (Table 2). The present results indicate local thickening for sites located in sectors of the ice sheet where Thomas and others (2000) also report thickening over larger spatial scales. Similarly, local ice-sheet thinning is indicated by the present results for sites located in regions where spatially averaged thinning is reported by Thomas and others (2000). There are quantitative differences in some calculated rates of thickness change when respective uncertainties are taken into account. At Crawford Point and Daugaard-Jensen Gletscher, the present results indicate faster rates of thinning than the regional estimates described by Thomas and others (2000). Differences in $\mathrm{d} H / \mathrm{d} t$ calculated using the two techniques reflect the large spatial variability in local mass balance across the Greenland ice sheet.

No direct comparisons can be made between the present results for Summit and South Dome and those reported by Thomas and others (2000). These sites are located on ice divides (Fig. 1) rather than within catchment regions. However, the near-steady-state behavior at Summit indicated by the present results is consistent with the regional pattern of very small rates of $\mathrm{d} H / \mathrm{d} t$ in central North Greenland described by Thomas and others (2000). At South Dome, a relatively fast rate of local ice-sheet thickening $\left(\sim 0.12 \mathrm{~m} \mathrm{a}^{-1}\right)$ is calculated. This site lies on the ridge separating a zone of regional thickening to the west from a zone of rapid regional thinning to the east and southeast (Thomas and others, 2000). The present result, then, is not inconsistent in the context of contrasting regional changes in this part of the ice sheet.

A comparison between all four PARCA estimates of mass balance (including a limited number of the present results) yields a mixed outcome according to Thomas and others (2001a). The best agreements are between the local rates of $\mathrm{d} H / \mathrm{d} t$ and the regional estimates of thickness changes as described above and illustrated in Table 2. There are large differences between mass-balance estimates derived from the two altimetry techniques, due in part to temporal changes in snow accumulation between the two measurement intervals (Thomas and others, 200la). Careful interpretation of altimetry results is necessary because the measurements are made over short time intervals. McConnell and others (2000) and Davis and others (2001) report that some of the slow elevation increase observed in altimetry surveys over the central southern part of the Greenland ice sheet may be due to increased snow accumulation over the last decade. When the altimetry estimates and the input-output estimates are recalculated to refer to overlapping spatially averaged areas, Thomas and others (200la) report an acceptable agreement to within combined error limits.

Comparison of the present results with other techniques provides another mixed outcome. At Camp Century, the present rapid thinning rate is inconsistent with a slow thickening rate interpreted by Budd and others (1971) from borehole temperature profiles, but agrees with a thinning of this part of the ice sheet inferred from air content in the Camp Century core (Raynaud and Whillans, 1981). The near-steady-state behavior at Summit is consistent with the modeled response of the central Greenland ice sheet to external forcings since the Last Glacial Maximum (Cuffey and Clow, 1997) and is similar to the steady-state conditions reported by Hvidberg and others (1997) for a site $\sim 25 \mathrm{~km}$ to the east. Seckel (1977) reports a slow thickening of the ice sheet close to the Crawford Point site, based on elevation changes measured over 9 years, that does not agree with the present calculation of longer-term thinning. This disagreement might be caused by decadal-scale variability in accumulation rates.

The broad pattern of thinning near the periphery and in outlet glacier catchments, and steady-state to slow thickening in the higher-elevation interior, derived from the present results is consistent with the pattern described by Krabill and others (2000). These authors attribute thinning near the periphery to altered ice flow, perhaps because of enhanced creep due to warmer and hence weaker Holocene-age ice now reaching the outer portions of the ice sheet. An alternative explanation is suggested by Thomas and others (2001b), noting that the fastest rates of thinning are found in the southeastern part of the ice sheet (Thomas and others, 2000). Horizontal velocities are consistently faster here than elsewhere in Greenland, indicating that much of the total motion takes place by basal sliding. Rapid changes in ice flow are thus more likely and are a possible explanation for the substantial thinning of this region of the ice sheet.

\section{GONGLUSIONS}

Local rates of ice-sheet thickness change have been obtained for 10 sites in Greenland by comparing measured vertical velocities and snow-accumulation rates. The results range from rapid thinning of a few decimeters per year to relatively slower rates of thickening. There is a great deal of variability between the sites, although a broad pattern emerges of icesheet thinning near the periphery and in outlet glacier catchments, and steady-state conditions or slow thickening in the high-elevation interior.

Uncertainties in the calculated rates of thickness change range from 0.02 to $0.21 \mathrm{~m} \mathrm{a}^{-1}$. Results for Summit, where each 
quantity is measured with confidence, have the smallest uncertainties. At other sites, the error budget is dominated by uncertainties in accumulation rate. Sites located in fast-flowing regions of the ice sheet also have relatively larger uncertainties because of errors associated with adjustments for along-slope flow. In principle, uncertainties can be reduced by the careful acquisition of additional accumulation-rate records and by extending the interval of velocity observations.

The present results provide rates of ice-sheet thickness change over time-scales equal to the lengths of the snowaccumulation records. Most records are a few decades long, although records spanning the past few centuries are used at the Humboldt, Camp Century and NASA/U sites. The accumulation-rate record at Summit is several millennia in length. Thus, the result from Summit is relevant to the response time of the ice sheet. For all other sites, the results indicate changes in ice thickness over the last $\sim 100$ years.

Local rates of ice-sheet thickness change are qualitatively comparable with regional estimates of $\mathrm{d} H / \mathrm{d} t$ reported by Thomas and others (2000). Quantitative differences in rates of thickness change between the two techniques illustrate the locally variable nature of ice-sheet mass balance in Greenland.

\section{AGKNOWLEDGEMENTS}

B. Spikes and S. Price assisted in the field. We thank fellow PARCA investigators for supplying the necessary supporting data. R. Thomas provided a thorough review that improved the manuscript. Support was provided by NASA's Polar Research Program through grants NAG5-5037 and NAG5-6838. This is Byrd Polar Research Center contribution C-1267.

\section{REFERENGES}

Arthern, R. A. and D. J. Wingham. 1998. The natural fluctuations of firn densification and their effect on the geodetic determination of ice sheet mass balance. Climatic Change, 40(4), 605-624.

Bales, R. C., J. R. McConnell, E. Mosley-Thompson and G.W. Lamorey. 2001a. Accumulation map for the Greenland ice sheet: 1971-1990. Geophys. Res. Lett., 28(15), 2967-2970.

Bales, R. C., J. R. McConnell, E. Mosley-Thompson and B. Csatho. 2001b. Accumulation over the Greenland ice sheet from historical and recent records. 7. Geophys. Res., 106(D4), 33,813-33,826.

Budd, W. F., D. Jenssen and U. Radok. 1971. Reinterpretation of deep ice temperatures. Nature, 232(30), 84-85.

Cuffey, K. and G. D. Clow. 1997. Temperature, accumulation and ice sheet evolution in central Greenland through the last deglacial transition. $\mathcal{F}$. Geophys. Res., 102(C12), 26,383-26,396.

Davis, C. H., C. A. Kluever and B. J. Haines. 1998. Elevation change of the southern Greenland ice sheet. Science, 279(5359), 2086-2088.

Davis, C. H., J. McConnell, J. Bolzan, J. Bamber, R. H. Thomas and E. Mosley-Thompson. 2001. Elevation changes of the southern Greenland ice sheet from 1978 to 1988: interpretation. F. Geophys. Res., 106(D24), 33,743-33754.

Hamilton, G. S. and I. M. Whillans. 2000. Point measurements of mass balance of the Greenland ice sheet using precision vertical global positioning system (GPS) surveys. 7. Geophys. Res., 105(B7), 16,295-16,301.

Hamilton, G. S., I. M. Whillans and P. J. Morgan. 1998. First point measurements of ice-sheet thickness change in Antarctica. Ann. Glaciol., 27, 125-129.

Hodge, S. M., D. L. Wright, J. A. Bradley, R.W. Jacobel, N. Skou and B. Vaughn. 1990. Determination of the surface and bed topography in central Greenland. F. Glaciol., 36(122), 17-30.

Hvidberg, C. S., K. Keller, N. S. Gundestrup, C. C. Tscherning and R. Forsberg 1997. Mass balance and surface movement of the Greenland ice sheet at Summit, central Greenland. Geophys. Res. Lett., 24(18), 2307-2310.

Krabill, W. B., R. H. Thomas, C. F. Martin, R. N. Swift and E. B. Frederick. 1995. Accuracy of airborne laser altimetry over the Greenland ice sheet. Int. 7. Remote Sensing, 16(7), 1211-1222.

Krabill, W. and 9 others. 2000. Greenland ice sheet: high-elevation balance and peripheral thinning. Science, 289(5478), 428-430.

McConnell, J. R. and 7 others. 2000. Changes in Greenland ice sheet elevation attributed primarily to snow accumulation variability. Nature, 406(6798), 877-879.

Meese, D. A. and 8 others. 1994. The accumulation record from the GISP2 core as an indicator of climate change throughout the Holocene. Science, 266(5191), 1680-1682.

Mosley-Thompson, E. and 8 others. 2001. Local to regional-scale variability of Greenland accumulation from PARCA cores. 7. Geophys. Res., 106(D24), 33,839-33,852.

Paterson, W. S. B. 1994. The physics of glaciers. Third edition. Oxford, etc., Elsevier.

Raynaud, D. and I. M. Whillans. 1981. Total gas content of ice and past changes of the northwest Greenland ice sheet. [Abstract.] International Association of Hydrological Sciences Publication 131 (Symposium at Canberra 1979 - Sea Level, Ice and Climatic Change), 235-237.

Seckel, H. 1977. Höhenänderungen im grönländischen Inlandeis zwischen 1959 und 1968. Medd. Gronl., 187(4).

Thomas, R. and 6 others. 2000. Mass balance of the Greenland ice sheet at high elevations. Science, 289(5478), 426-428.

Thomas, R. and 7 others. 200la. Mass balance of higher-elevation parts of the Greenland ice sheet. 7. Geophys. Res., 106(D24), 33,707-33,716.

Thomas, R.H. and PARCA Investigators. 2001b. Program for Arctic Regional Climate Assessment (PARCA): goals, key findings and future directions. 7. Geophys. Res.

Van der Veen, C. J. and J. F. Bolzan. 1999. Interannual variability in net accumulation on the Greenland ice sheet: observations and implications for mass balance measurements. F. Geophys. Res., 104(D2), 2009-2014.

Wingham, D. J., A. L. Ridout, R. Scharroo, R. J. Arthern and C. K. Shum. 1998. Antarctic elevation change 1992 to 1996. Science, 282(5388), 456-458.

Zumberge, J. F., M. B. Heflin, D. C. Jefferson, M. M. Watkins and F. H. Webb. 1997. Precise point positioning for the efficient and robust analysis of GPS data from large networks. 7. Geophys. Res., 102(B3), 5005-5017.

Zwally, H. J., A. C. Brenner and J. P. DiMarzio. 1998. Technical comment: growth of the southern Greenland Ice Sheet. Science, 281(5381), 1251. 